\title{
ACHIEVEMENT MOTIVATION AND THE EEG SPECTRAL POWER
}

Pavel N. Ermakov, Elena V. Vorobyeva

Southern Federal University Rostov-on-Don

\begin{abstract}
Achievement motivation is a psychological category which implies a desire to achieve significant (powerful) results in certain sphere. According to the results of psychophysiological research people who are motivated for success are very active before they are instructed by the researcher which proves that they aimed at the perception of the referent situation and the intense level of expectations. One of the vital issues today is a problem how genes influence human behaviour. Thus on the basis of contemporary researches we can conclude that such influence is regulated by brain processes.
\end{abstract}

Keywords: achievement motivation, brain process, psychology.

Achievement motivation is a psychological category which implies a desire to achieve significant (powerful) results in certain sphere. According to the results of psychophysiological research people who are motivated for success are very active before they are instructed by the researcher which proves that they aimed at the perception of the referent situation and the intense level of expectations. In recent years there have been published several works where the degree of achievement motivation of the individual is related with the activation of the brain dopamine system (Tomer et al., 2008). In the given work some features of The EEG spectral power are considered in reference with the performance of verbal operations (verbal associative activity and mental arithmetic) in individuals with different level of achievement motivation.

One of the vital issues today is a problem how genes influence human behaviour. Thus on the basis of contemporary researches we can conclude that such influence is regulated by brain processes. Intermedi- 
ate phenotypes are the factor that allows to study genes and behaviour in close relationship (Aleksandrov, 2009).

EEG studies correlate with various kinds of cognitive activity that allows to better understand psychophysiological mechanisms which it is caused by (Razumnikova et al., 2009). So, performance of verbal operations is carried out with obligatory participation of various departments of both hemispheres of the brain cortex. Performance of the verbal task is connected with the increase of thetal spectral power (Razumnikova et al., 2009). The analysis of the EEG dynamics by mental arithmetic has shown left-sided activation of the temporal, central, parietal cortex (Inouye et al., 1995), and also activation of the parietal cortical areas.

In our earlier works we studied EEG characteristics and event-related potentials within mainstream achievement motivation while recording electrophysiological parameters; and we also studied the results of the twin method.

In this paper we consider the characteristics of the The EEG spectral power while recording verbal operations (verbal associative operations and mental arithmetic) by the individuals with different levels of achievement motivation. The twin method allows to estimate the components of phenotypic variance of the propertied studied.

Procedure and Research Methods. In our research there participated 102 monozygotic twin pairs (MZ) at the age from 14 till 26 years (among which there were 48 male pairs and 54 female pairs), 98 dizygotic twin pairs (DZ) (among which there were 46 male pairs and 52 female pairs). Average age is 18,6 years. For defining zygosity we used the twin method of polysimptomic similarities. Diagnosis of achievement motivation was carried out using the "achievement motivation" questionnaire developed by A. Mehrabian. To register the electrical activity of the brain 21 electrodes were used (Fp1, Fp2, Fpz, F3, F4, Fz, F7, F8, C3, C4, Cz, P3, P4, Pz, T3, T4, T5, T6, O1, O2, Oz), monopolar scheme with ipsilateral ear referents was applied. The "Encefalan" electroencephalograph manufactured by "Medicom", (Taganrog city, Russia) was used. The EEG filtration was carried out in the range of 0,5-70 Hz. The sequence of functional EEG tests are as follows: "background", "to open the eyes", "to close the eyes", "verbal associations" test (making up words which start with the letter "a"), "Mental arithmetic" test (consecutive addition of number 7). For tracing and suppression of EEG artifacts, ECG, EMG, EOG recordings were used. The analysis of the absolute The 
EEG spectral power was carried out by comparison of the background test indicators with functional ranges in the same frequency (delta- 1 $(0,5-2,0 \mathrm{~Hz})$, delta-2 $(2,0-4,0 \mathrm{~Hz})$, theta-1 $(4,0-6,0 \mathrm{~Hz})$, theta-2 $(6,0-8,0$ $\mathrm{Hz})$, alpha-1 $(8,0-10,5 \mathrm{~Hz})$, alpha-2 $(10,5-13,0 \mathrm{~Hz})$ beta- $1(13,0-24,0 \mathrm{~Hz})$, beta-2 $(24,0-35,0 \mathrm{~Hz})$.

\section{The Research Results}

The power of the total range of alpha rhythm $(8-13 \mathrm{~Hz})$ in twins was in the right and left occipital areas $34,5 \pm 16,9$ and $33,4 \pm 15,9 \mathrm{mkv}^{2}$.

By the Student's t-test the reliability analysis of the The EEG spectral power distinctions showed that the significant increase of the EEG power in the sample of "verbal associations" in comparison with the background in the range of deltal occurs at $\mathrm{O} 1(\mathrm{~T}=2,56, \mathrm{p}<0,05), \mathrm{P} 3(\mathrm{~T}=2,88$, $\mathrm{p}<0,05), \mathrm{C} 3(\mathrm{~T}=2,44, \mathrm{p}<0,05), \mathrm{T} 5(\mathrm{~T}=2,74, \mathrm{p}<0,05), \mathrm{Cz}(\mathrm{T}=2,49, \mathrm{Pz}$ $(\mathrm{T}=2,24, \mathrm{p}<0,05), \mathrm{F} 7(\mathrm{~T}=3,06, \mathrm{p}<0,05)$, $\mathrm{T} 3(\mathrm{~T}=2,62, \mathrm{p}<0,05)$ (advantage of the left hemisphere); in delta2 range at $\mathrm{C} 3(\mathrm{~T}=2,42, \mathrm{p}<0,05)$, $\mathrm{F} 4(\mathrm{~T}=2,06, \mathrm{p}<0,05), \mathrm{F} 3(\mathrm{~T}=2,67, \mathrm{p}<0,05), \mathrm{Fp} 1(\mathrm{~T}=2,19, \mathrm{p}<0,05), \mathrm{F} 8$ $(\mathrm{T}=2,00, \mathrm{p}<0,05), \mathrm{F} 7(\mathrm{~T}=2,16, \mathrm{p}<0,05), \mathrm{Fz}(\mathrm{T}=2,20, \mathrm{p}<0,05)$.

In the sample of "mental arithmetic" in the range of deltal significant increase in power compared to the background occurs at $\mathrm{T} 5(\mathrm{~T}=2,49$, $p<0,05)$, T3 $(T=2,47, p<0,05)$ (advantage of the left hemisphere). Significant increase of delta 2 spectral power in comparison with the background occurs at T5 $(\mathrm{T}=2,09, \mathrm{p}<0,05), \mathrm{T} 6(\mathrm{~T}=2,21, \mathrm{p}<0,05), \mathrm{C} 3(\mathrm{~T}=2,50$, $\mathrm{p}<0,05), \mathrm{C} 4(\mathrm{~T}=3,26, \mathrm{p}<0,05), \mathrm{Cz}(\mathrm{T}=3,08, \mathrm{p}<0,05), \mathrm{F} 8(\mathrm{~T}=3,26, \mathrm{p}$ $<0,05)$, T3 $(\mathrm{T}=2,04, \mathrm{p}<0,05), \mathrm{T} 4(\mathrm{~T}=3,01, \mathrm{p}<0,05), \mathrm{F} 3(\mathrm{~T}=2,43, \mathrm{p}<0,05)$, $\mathrm{F} 4(\mathrm{~T}=4,31, \mathrm{p}<0,05), \mathrm{Fz}(\mathrm{T}=2,24, \mathrm{p}<0,05)$ (both hemispheres are presented). The significant increase of thetal spectral power in comparison with the background occurs at $\mathrm{O} 2(\mathrm{~T}=2,07, \mathrm{p}<0,05), \mathrm{Oz}(\mathrm{T}=2,75, \mathrm{p}$ $<0,05), \mathrm{P} 3(\mathrm{~T}=2,77, \mathrm{p}<0,05), \mathrm{P} 4(\mathrm{~T}=3,27, \mathrm{p}<0,05), \mathrm{Pz}(\mathrm{T}=2,42, \mathrm{p}<0,05)$, T5 ( $\mathrm{T}=3,14, \mathrm{p}<0,05), \mathrm{T} 6(\mathrm{~T}=2,26, \mathrm{p}<0,05), \mathrm{C} 3(\mathrm{~T}=2,72, \mathrm{p}<0,05), \mathrm{C} 4$ $(\mathrm{T}=3,75, \mathrm{p}<0,05), \mathrm{Cz}(\mathrm{T}=4,85, \mathrm{p}<0,05), \mathrm{F} 7(\mathrm{~T}=3,20, \mathrm{p}<0,05), \mathrm{F} 8(\mathrm{~T}=2,89$, $\mathrm{p}<0,05), \mathrm{T} 3(\mathrm{~T}=3,05, \mathrm{p}<0,05), \mathrm{F} 3(\mathrm{~T}=3,40, \mathrm{p}<0,05), \mathrm{F} 4(\mathrm{~T}=3,44, \mathrm{p}$ $<0,05), \mathrm{Fz}(\mathrm{T}=3,45, \mathrm{p}<0,05)$.

Achievement Motivation and Background EEG. The results of the one-factorial dispersive analysis (an independent variable: level of selfattributed achievement motivation in twins ( 3 scales: 1 - motivation of avoiding failures, 2 - average level of achievement motivation, 3 - mo- 
tivation of aspiration to success; a dependent variable - absolute values of spectral power of biopotentials in the background sample, $\mathrm{mkv}^{2}$ ) showed that there are significant distinctions in the The EEG spectral power in twins with different level of achievement motivation: in delta1 at P4 $(\mathrm{F}=3,17, \mathrm{p}<0,05), \mathrm{C} 4(\mathrm{~F}=3,41, \mathrm{p}<0,05), \mathrm{T} 6(\mathrm{~F}=3,71, \mathrm{p}<0,05), \mathrm{T} 4$ $(\mathrm{F}=4,19, \mathrm{p}<0,05), \mathrm{F} 8(\mathrm{~F}=3,49, \mathrm{p}<0,05)$; in delta2 at $\mathrm{P} 3(\mathrm{~F}=3,42, \mathrm{p}<0,05)$, $\mathrm{Pz}(\mathrm{F}=3,43, \mathrm{p}<0,05)$; in theta2 at $\mathrm{T} 3(\mathrm{~F}=3,68, \mathrm{p}<0,05)$; alpha1 at $\mathrm{Fp} 2$ $(\mathrm{F}=3,99, \mathrm{p}<0,05), \mathrm{Fpz}(\mathrm{F}=3,39, \mathrm{p}<0,05)$.

Thus in the range of deltal higher level of achievement motivation (striving for success) is appropriate to a higher the EEG spectral power. In contrast, at delta 2 and alpha 1 range, higher levels of achievement motivation corresponded to a lower EEG power (Fig. 1).

Figure 1 indicates that in individuals with severe motivated drive to success, the EEG showed a higher power of deltal range in the right hemisphere than in those without a dominant achievement motivation and
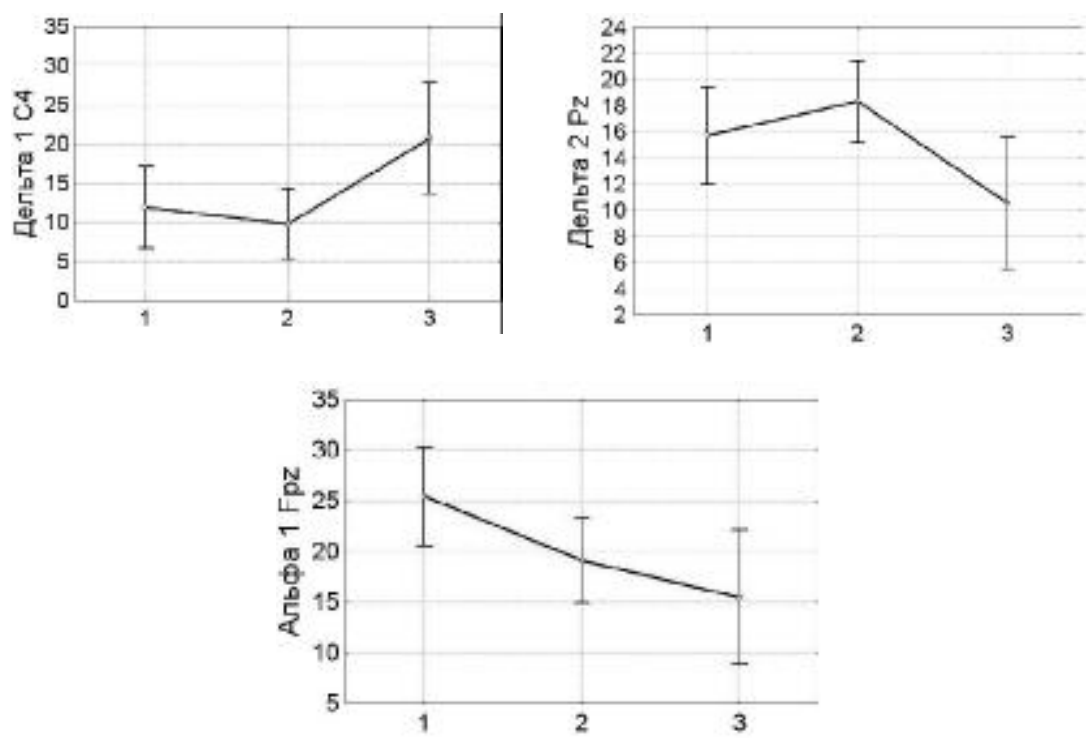

Figure 1. The results of the one-factorial dispersive analysis $(\mathrm{X}$ - an independent variable: level of self-attributed achievement motivation in twins $(1-$ motivation of avoiding failures, 2 - average level of achievement motivation, 3 - motivation of aspiration to success); $\mathrm{Y}$ - a dependent variable - absolute values of spectral power of biopotentials in EEG background sample, $\mathrm{mkv}^{2}$ ) 
those with the motivation of avoiding failure (which can be interpreted as a significant cortex activation of the right hemisphere of the subcortical structures). Individuals with severe failure in avoidance motivation, the EEG showed a higher power of alphal range in the anterior-frontal area than in individuals without the dominant achievement motivation and aspirations of people with the motivation to succeed. Individuals with an zero achievement motivation, the EEG showed a higher power of delta2 range in the parietal areas.

Achievement Motivation and the EEG in "Verbal Associations" Sample. The results of the one-factorial dispersive analysis (an independent variable: level of self-attributed achievement motivation of twin (3 scales: 1 - motivation of avoiding failures, 2 - average level of achievement motivation, 3 - motivation of aspiration to success; a dependent variable - absolute values of the spectral power of biopotentials in "verbal associations" sample, $\mathrm{mkv}^{2}$ ) showed that significant distinctions in the The EEG spectral power in twins with different levels of achievement motivation are registered in alpha 1 at $\mathrm{Fp} 2(\mathrm{~F}=5,46, \mathrm{p}<0,01), \mathrm{Fpz}(\mathrm{F}=3,95$, $\mathrm{p}<0,05), \mathrm{Fp} 1(\mathrm{~F}=3,43, \mathrm{p}<0,05), \mathrm{Oz}(\mathrm{F}=3,21, \mathrm{p}<0,05)$ (Fig. 2).
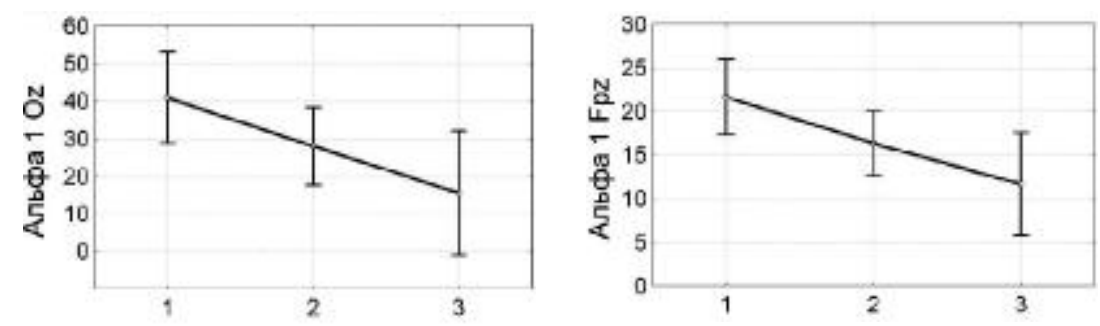

Figure 2. The results of the one-factorial dispersive analysis $(\mathrm{X}-$ an independent variable: level of self-attributed achievement motivation in twins $(1-$ motivation of avoiding failures, 2 - average level of achievement motivation, 3 - motivation of aspiration to success); $\mathrm{Y}$ - a dependent variable - absolute values of spectral power of biopotentials in "verbal associations" sample, $\mathrm{mkv}^{2}$ )

Figure 2 indicates that in individuals with severe failure avoidance motivation, the EEG showed much higher capacity of alpha 1 range in the anterior-frontal and occipital central areas than in individuals without the dominant achievement motivation and those ones with the motivation of striving for success. 
Achievement Motivation and the EEG in "The Mental Arithmetic" Sample. The results of the one-factorial dispersive analysis (an independent variable: level of self-attributed achievement motivation of twin (3 scales: 1 - motivation of avoiding failures, 2 - average level of achievement motivation, 3 - motivation of aspiration to success; a dependent variable - absolute values of spectral power of biopotentials in "the mental arithmetic" sample, $\mathrm{mkv}^{2}$ ) showed that significant distinctions in the EEG spectral power in twins with different level of achievement motivation are registered in delta1 at $\mathrm{T} 4(\mathrm{~F}=5,92, \mathrm{p}<0,01)$, T6 $(\mathrm{F}=3,24, \mathrm{p}<0,05), \mathrm{C} 4(\mathrm{~F}=3,24, \mathrm{p}<0,05), \mathrm{F} 4(\mathrm{~F}=3,19, \mathrm{p}<0,05), \mathrm{F} 8$ $(\mathrm{F}=4,47, \mathrm{p}<0,05)$; in delta2 at $\mathrm{T} 6(\mathrm{~F}=3,73, \mathrm{p}<0,05)$, T4 $(\mathrm{F}=3,61, \mathrm{p}$ $<0,05), F 8(F=4,00, p<0,05)$, and also in alpha1 at $\mathrm{Fp} 2(\mathrm{~F}=3,27, \mathrm{p}<0,05)$ (Fig. 3).

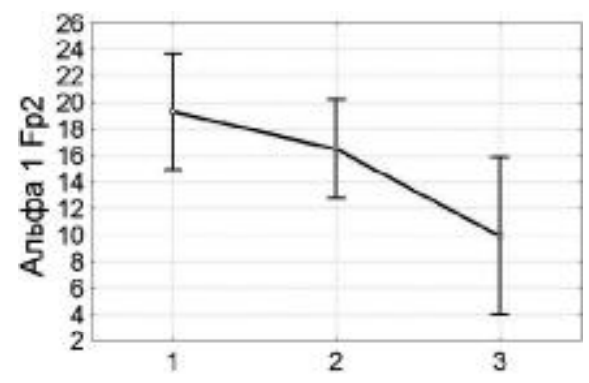

Figure 3. The results of the one-factorial dispersive analysis (X - an independent variable: level of self-attributed achievement motivation of twin ( 1 - motivation of avoiding failures, 2 - average level of achievement motivation, 3 - motivation of aspiration to success); Y - a dependent variable - absolute values of spectral power of biopotentials in "the mental arithmetic" sample, $\mathrm{mkv}^{2}$ )

Figure 3 indicates that in individuals with severe motivation of avoiding failures, the EEG showed much higher capacity of alpha 1 range in the anterior-frontal area to the right than in those ones who displayed zero dominant achievement motivation and success motivated. In individuals with severe motivated drive to success, the EEG showed much higher power of delta 1.2 range in the central, frontal and temporal areas of the right hemisphere. 
Genetic and Environmental Determinants of the EEG spectral power at Verbal Associative Activity and the Mental Arithmetic. Fig. 4-7 assess the results of the genotype contribution $\left(\mathrm{h}^{2}\right)$ of the general $\left(\mathrm{c}^{2}\right)$ and individual $\left(\mathrm{e}^{2}\right)$ environments to interindividual variability of the

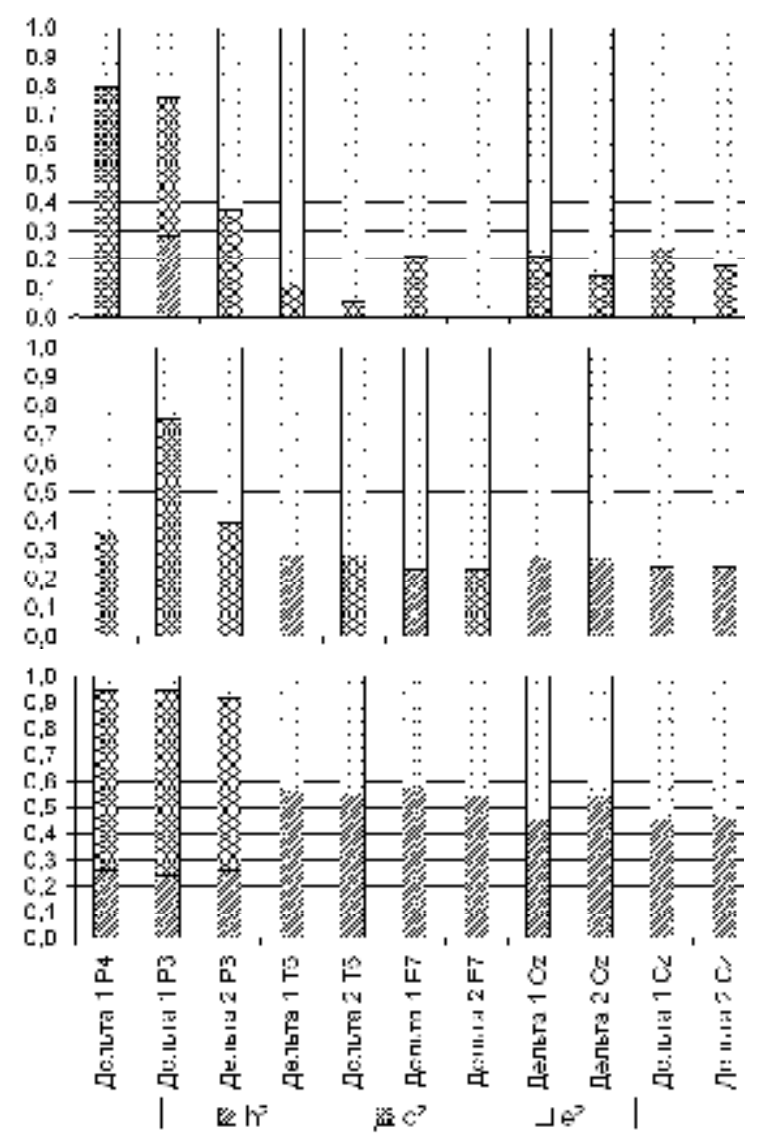

Figure 4. Indicators of the genotype contribution $\left(\mathrm{h}^{2}\right)$ of the general $\left(\mathrm{c}^{2}\right)$ and individual $\left(\mathrm{e}^{2}\right)$ environments to interindividual variability of delta spectral power in the background EEG (see below), EEG in the "verbal associations" sample (the second drawing below) and EEG in the "mental arithmetic" sample (the third drawing below) 


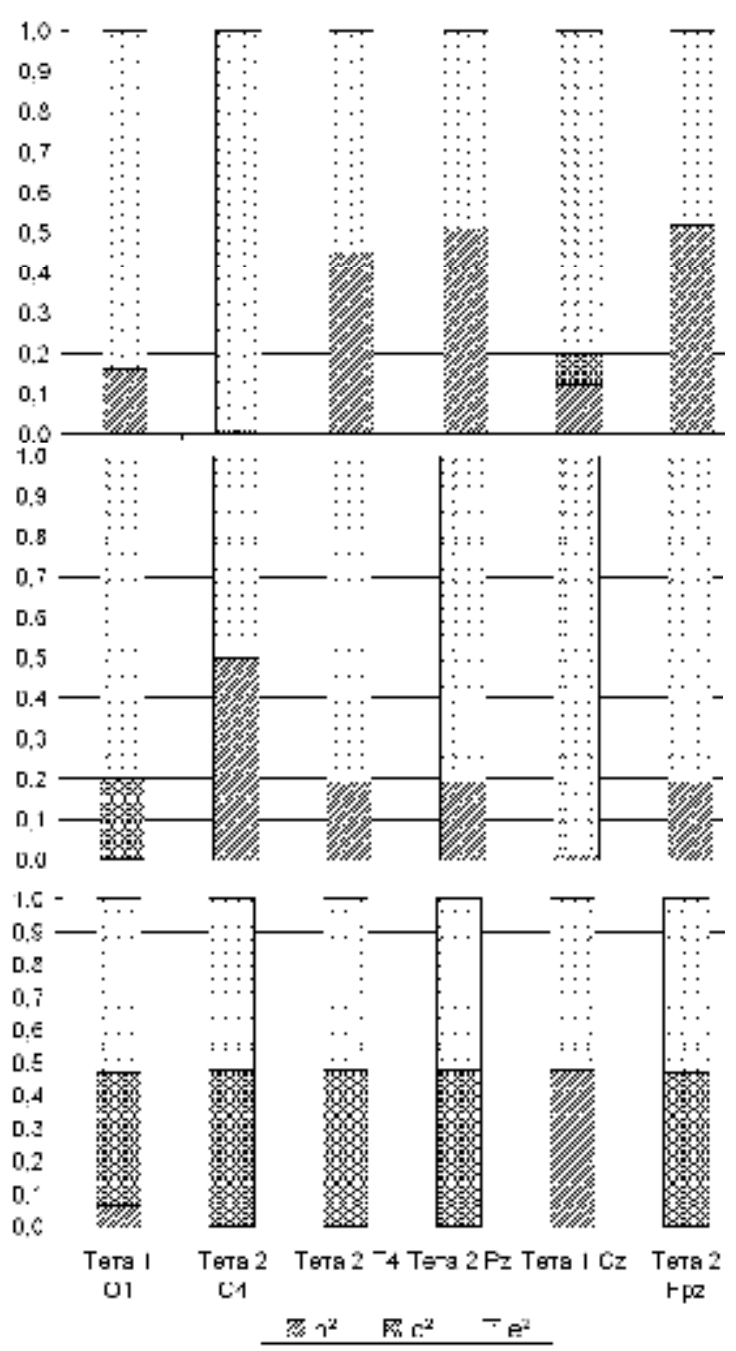

Figure 5. Indicators of the genotype contribution $\left(\mathrm{h}^{2}\right)$ of the general $\left(\mathrm{c}^{2}\right)$ and individual $\left(\mathrm{e}^{2}\right)$ environments to interindividual variability of theta rhythm spectral power in the background EEG (see below), EEG in "verbal associations" sample (the second drawing below) and EEG in "mental arithmetic" sample (the third drawing below) 
background EEG spectral power of delta, theta, alpha and beta rhythms in the course of carrying out "verbal associations" sample and "the mental arithmetic" sample. To estimate the dynamic nature of genetic and environmental determinants of the EEG spectral power in the course of verbal associative activity and the mental arithmetic in comparison with EEG background values we selected those assignments for which values of phenotypical dispersion components in all three tests were received. It was thus considered that if $\mathrm{r}(\mathrm{DZ})<0$ or $\mathrm{r}(\mathrm{MZ})>2 \mathrm{r}(\mathrm{DZ}), \mathrm{h}^{2}$ is equal to $\mathrm{r}(\mathrm{MZ})$; if $\mathrm{r}(\mathrm{MZ})<\mathrm{r}(\mathrm{DZ}), \mathrm{h}^{2}=0$; if $\mathrm{r}(\mathrm{MZ})<0, \mathrm{~h}^{2}$ is not calculated (M.S. Egorova, etc., 2004).

In the delta range in the course of verbal and associative activities compared with the baseline EEG recording there is a significant decrease in the indices of spectral power heritability in the parietal area bilaterally of the posterior temporal and lateral frontal areas of the left, as well as in the central occipital and central areas $(\mathrm{p}<0,05)$.

When performing mental arithmetic in the same areas there is even more significant decrease in the indices of spectral power heritability compared with the baseline values $(p<0.01)$ except for the left parietal area in which the index of spectral power heritability was not significantly different from the background values (Fig. 4 ).

In the theta range in the course of verbal and associative activities compared to the background there is a significant decrease in the indices of spectral power heritability in the central lead $\mathrm{Cz}(\mathrm{p}<0,01)$, as well as significant increases in indices of spectral power heritability in the central $(\mathrm{p}<0,01)$ and anterior temporal $(\mathrm{p}<0.05)$ areas of both the right and in the anterior frontal central areas $(\mathrm{p}<0,05)$.

When performing mental arithmetic in the central $(\mathrm{p}<0.01)$ and anterior-temporal $(\mathrm{p}<0,01)$ right areas and in the anterior frontal central area $(p<0,01)$ there is even more significant increase in indicators of spectral power heritability compared with the baseline values (Fig. 5).

In the alpha range in the course of verbal and associative activities compared to the background values there is a significant decrease in the indices of spectral power heritability in the posterior temporal and lateral frontal areas in the left $(\mathrm{p}<0,05)$ in the central and central occipital areas $(\mathrm{p}<0,05)$.

In the course of mental arithmetic sample there are no significant differences in indicators of spectral power heritability compared with the background values (Figure 6). 

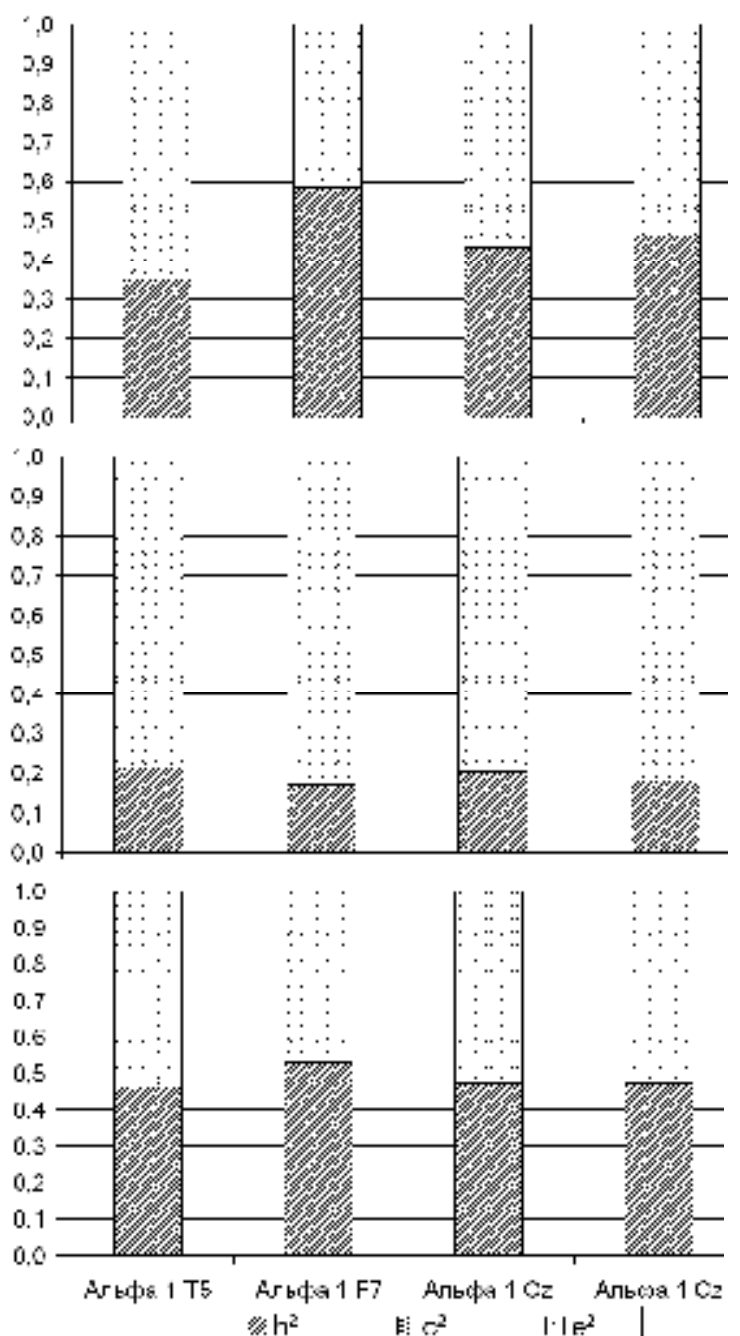

Figure 6. Indicators of the genotype contribution $\left(h^{2}\right)$ of the general $\left(c^{2}\right)$ and individual $\left(\mathrm{e}^{2}\right)$ environments to interindividual variability of alpha spectral power an in the background EEG (see below), EEG in "verbal associations" sample (the second drawing below) and EEG in "mental arithmetic" sample (the third drawing below) 


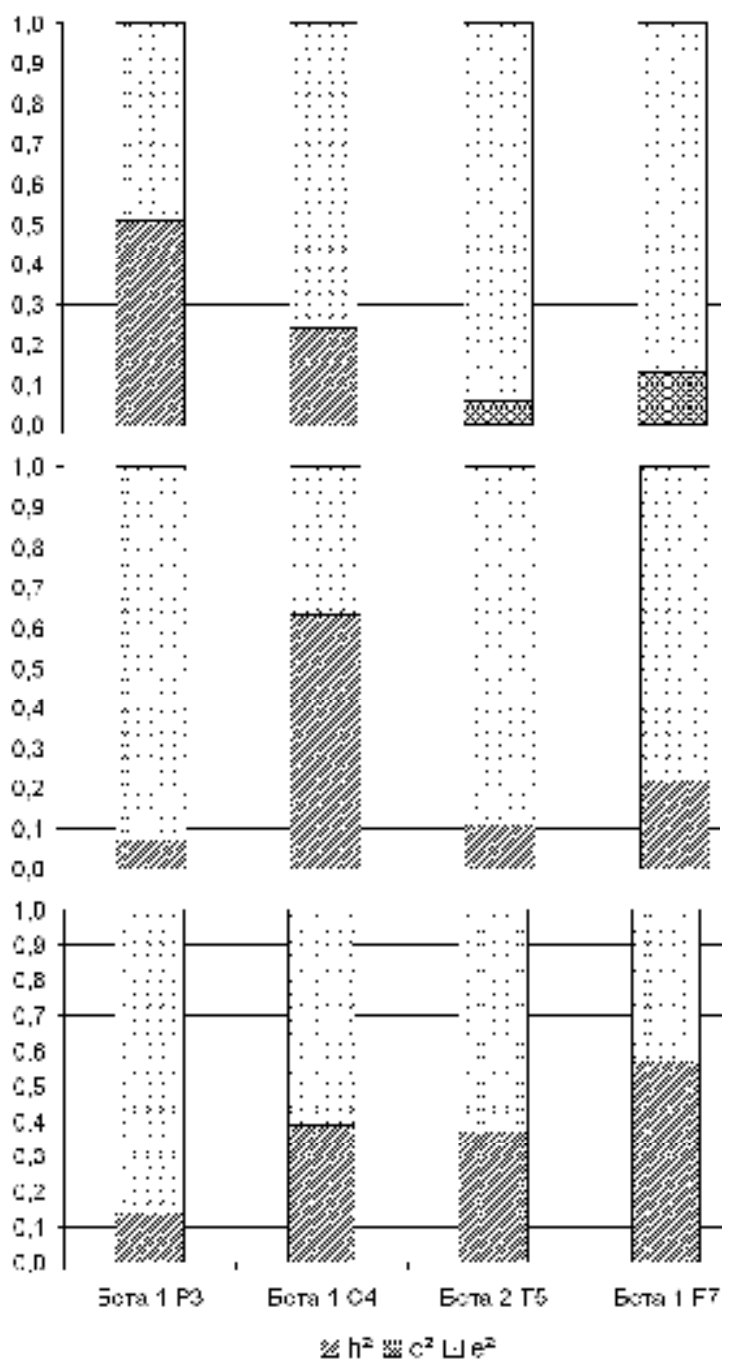

Figure 7. Indicators of the genotype contribution $\left(\mathrm{h}^{2}\right)$ of the general $\left(\mathrm{c}^{2}\right)$ and individual $\left(\mathrm{e}^{2}\right)$ environments to interindividual variability of beta spectral power in background EEG (see below), EEG in "verbal associations" sample (the second drawing below) and EEG in "mental arithmetic" sample (the third drawing below) 
The data analysis showed that significant changes occur predominantly in the betal range. Thus, the betal range in the course of verbal and associative activities of the genotype influence is lower and the role of the individual environment is higher in the posterior temporal and lateral frontal areas in the left $(\mathrm{p}<0,05)$. In contrast, in the right central lead $\mathrm{C} 4$ there is a significant increase in the genotype influence $(\mathrm{p}<0,05)$.

When performing mental arithmetic there is a significant increase in spectral power heritability indicators compared with the baseline values observed in the left parietal area $(p<0,01)$, thus there is a significant reduction of spectral power heritability indicators in the posterior-tempo$\mathrm{ral}(\mathrm{p}<0,05)$ and in the left frontal areas $(\mathrm{p}<0,01)$ (Fig. 7$)$.

\section{Conclusion}

Our research has shown that in individuals with severe motivation of avoiding failures the EEG provides quite high values of the spectral power of alpha 1 range (compared with other individuals), while this relation persists in conditions when cognitive load is rather high. It is interesting to correlate our findings with the results of work performed by E.A. Umryuhin et al, where high efficiency performance of tests based on rather high abilities of memorizing and high prediction power a low-frequency alpha rhythm was discovered. In a number of works performed by O.M. Razumnikova it has also been considered that the big power of a low-frequency alpha values is connected with higher verbal creativity (Razumnikova et al., 2009). Hence, low-frequency alpha values in background EEG is not only the indicator of successful performance of similar cognitive tasks, but it also indicates motivation of avoiding failure. Individuals with severe motivated drive to succeed are more commonly found in comparison others. The EEG spectral power values in the delta range of frequencies are dominating in the right hemisphere (as in the background sample, and in carrying out the mental arithmetic). In individuals with average achievement motivation (without dominant motivation desire to succeed or avoid failure) in the background sample there was observed a significantly higher level of the EEG spectral power of delta2 range. Changes in the delta range may be associated with the processes of decision making (Basar et al., 2001). In clinical studies a dependence 
of EEG spectral power of delta range on the content of emotional stimulation was observed.

The analysis of the EEG spectral power by Student's $t$-test showed that in the course of inventing verbal associations there is a significant increase in betal (bilaterally in the central cortex area, the left temporal assignments and in the left frontal assignment), and also in theta rhythm (bilaterally in the frontal cortical area). On the whole, it is possible to conclude that in the course of verbal associations task performance frontal, central and temporal cortical areas of the both brain hemispheres with the advantage of the left hemisphere were activated.

In the course of arithmetic operations performance there are observed significant changes of theta power in temporal, parietal and occipital areas, and also changes of beta1values in central and left parietal cortical areas.

We can arrive to a conclusion that the EEG parameters are designed to describe psychophysiological features throughthe performance of arithmetic operations. The data obtained in the course of the research carried out correspond to the results of the researches which deal with the studies of cerebral organization of arithmetic operations (Inouye et al., 1995; Fernandez et al., 1995; Dahaene et al., 1999).

The increasing theta rhythm indicates the emotional and motivational excitation when an individual is performing as arithmetic operation. Furthermore, activation of the temporal, parietal and occipital areas may be associated with the high brain activity aimed at the successful cognitive performance in highly motivated individuals.

The sources of theta rhythm include hypothalamus, hippocampus, reticular formation and stem structures (Vinogradova, 1995; Sauseng \& Klimesch, 2008). The theta role as an active filter in the process of information selection and registration is shown. The increase in theta activity connected with verbal memory activity is shown in a number of works (Jensen \& Tesche, 2002; Raghavachari et al., 2006). Frontal and temporal parietal areas participate in the course of verbal tasks performance. The increase in theta spectral power probably reflects the activity of «anterior attention system» (Posner \& Petersen, 1990). According to the existing representations based on the empirical studies this system is located in the frontal cortical areas which are connected with the limbic and frontal motivational systems of the brain; it corresponds to the functions of 
volutionary attention. Contemporary researches show that theta power correlates with the information processing such as encoding and search for verbal stimuli (Kahana, 2006). The data obtained is similar to the results of studies carried by O.M. Razumnikova. They show that the task of inventing words starting with certain letter contributes to the increase in thetal power. According to clinical researches the increase in theta range is connected with stem structures activity, whereas beta range is associated with sub-cortical structures.

Recent studies show that the beta rhythm is associated with volutionary attention (Wróbel et al., 2007) or cognitive processes. Various sources for beta 1 and beta 2 are shown. So, for betal and alpha there are similar sources which are the back departments of the hemispheres. Beta2's source is located deeper in the brain and is more frontal which is similar to theta one (Lehmann \& Michel, 1990). In the studies conducted by W.Ray and H.Cole it was observed that betal activity increases in the right hemisphere when individuals are solving problems of spatial type and in the left hemisphere while they are solving analytical tasks. Moreover, if the problem is emotionally coloured, there is a great expression of betal activity in the parietal and temporal brain areas (Ray \& Cole, 1985).

The analysis of the psychogenetic data allows to conclude that verbal associative activity is connected with changing values of the heritability of the EEG spectral power predominantly in the left hemisphere. In betal in the course of verbal associative activity there is a change of parity of genetic and environmental factors, reduction of heritability of betal spectral power in central frontal and temporal areas in the left, and also there is an increase in a corresponding indicator in the central area in the right. In the course of associative activity there is an increase in heritability theta2 spectral power, and also there is a reduction of corresponding thetal value in the temporal, frontal and central occipital areas with the advantage of the left hemisphere. In the animals studies the data were obtained on the relationship of gene expression of GABAergic neurotransmitter systems of the brain with the power of the deltarhythms in sleep deprivation (Wisor et al., 2006).

In psychogenetic studies there is age dynamics of the genotype and environmental indicators in the phenotypic variability of the EEG 
spectral characteristics, while the heritability growth rate increases if the number of participants increases and the stress rate also increases. According to Y. Tang etc. (Tang et al., 2007) heritability values of the EEG spectral power were in the range between 0.22 and 0.65 and had high values for all assignments and frequency ranges (from theta (3-7 $\mathrm{Hz})$ to a high-frequency beta range $(20-28 \mathrm{~Hz})$ ). Thus in the range of theta-frequencies higher indicators of heritability were received for the frontal and central areas. Heritability estimations in low-frequency and high-frequency alpha values are observed, and also low-frequency beta are rather high in the frontal and central areas with the increase in heritability indicator from central to parietal and to occipital areas. In highfrequency beta range in the central cortical area the heritability value is higher than in the periphery of the same area.

In recent years we have achieved a better understanding of the basic laws of interaction between genotype and environmental factors in the course of evolution, according to which in the problem environment in a number of generations there is an accumulation of genes that facilitate the behaviour in these conditions, whereas the environmental factors are less important and they consequently trigger genetic assimilation (Anokhin, 2009).

\section{References}

Alexandrov, J.I. (2009). Sistemnaja struktura individual'nogo opyta kak otrazhenie istorii ego formirovanija [System structure of individual experience as reflexion of history of its formation]. In Almanah "Novye issledovanija": Materialy mezhdunarodnoj konferencii "Fiziologija razvitija cheloveka" [Almanac "New researches": Materials of the international scientific conference "Physiology of development of the person"], 2(19) (pp. 15-16). Moscow: Verdana.

Anokhin, A.P. (2009). Genetics and development of frontal brain function in adolescence: implications for self-regulation of behavior. In Al'manah "Novye issledovanija": Materialy mezhdunarodnoj konferencii "Fiziologija razvitija cheloveka" [Almanac "New researches": Materials of the international scientific conference "Physiology of development of the person"], 2(19) (pp. 14-15). Moscow: Verdana.

Basar, E., Basar-Eroglu, C., Karakas, S., \& Schurmann, M. (2001). Gamma, alpha, delta, and theta oscillations govern cognitive processes. Int. J. Psychophysiol., 39, 241248. 
Dahaene, S., Spelke, E., Pinel, P., Stanescu, R., \& Tsivkin S. (1999). Sources of mathematical thinking: behavioral and brain-imaging evidence. Science, 284, 970974.

Egorova, M.S, Zyrjanova, N.M., Parshikova, O.V, Pjankova, S.D., \& Tchertkova, J.D. (2004). Genotype. Environment. Development. Moscow: OGI.

Fernandez, T., Harmony, T., Rodriguer, M. et al. (1995). EEG activation patterns during the performance of tasks in different components of mental calculation. EEG and Clin. Neurophysiol., 93(3), 175-181.

Inouye, T., Toi, S., \& Matsumoto, Y. (1995). A new segmentation method of electroencephalograms by use of Akaike's information criterion. Cognitive Brain Research, 3(1), 33-40.

Jensen, O., \& Tesche, C.D. (2002). Frontal theta activity in humans increases with memory load in a working memory task. Eur. J. Neurosci., 15, 1395-1399.

Kahana, M.J. (2006). The Cognitive Correlates of Human Brain Oscillations. The Journal of Neuroscience, 26(6), 1669-1672.

Lehmann, D., \& Michel, C.M. (1990). Intracerebral dipole source localization for FFT power maps. EEG Clin. Neurophysiol., 76, 271-276.

Posner, M., \& Petersen, S. (1990). The attention system of the human brain. Annual Review of Neuroscience, 13, 25-42.

Raghavachari, S., Lisman, J.E., Tully, M., Madsen, J.R., Bromfield, E.B., \& Kahana, M.J. (2006). Theta Oscillations in Human Cortex During a Working-Memory Task: Evidence for Local Generators. J. Neurophysiol., 95, 1630-1638.

Ray, W., \& Cole, H. (1985). EEG alpha activity reflects attention demands and beta activity reflects emotional and cognitive processes. Science, 228, 750-752.

Razumnikova, O.M, Volf, N.V., \& Tarasova, I.V. (2009). Strategija i rezul'tat: polovye razlichija $\mathrm{v}$ jelektrograficheskih korreljatah verbal'noj i obraznoj kreativnosti [Strategy and result: Genderual distinctions in electrographic correlates verbal and figurative creation]. Fiziologiya cheloveka, 35(3), 31-41.

Sauseng, P., \& Klimesch, W. (2008). What does phase information of oscillatory brain activity tell us about cognitive processes? Neuroscience and Biobehavioral Reviews, 32(5), July, 1001-1013.

Tang, Y., Chorlian, D.B., Rangaswamy, M., Porjesz, B., Bauer, L., Kuperman, S., O’Connor, S., Rohrbaugh, J., Schuckit, M., Stimus, A., \& Begleiter, H. (2007). Genetic influences on bipolar The EEG power spectra. International Journal of Psychophysiology, 65, 2-9.

Tomer, R., Goldstein, R.Z., Wang G.-J., Wong, C., \& Volkow, N.D. (2008). Incentive motivation is associated with striatal dopamine asymmetry. Biological Psychology, 77, 98-101. 
Vinogradova, O.S. (1995). Expression, control and probable functional significance of the neuronal theta-rhythm. Progress in Neurobiology, 45, 523-583.

Wisor, J.P., Morairty, S.R., Huynh, N.T., Steininger, T.L., \& Kilduff, T.S. (2006). Gene expression in the rat cerebral cortex: comparison of recovery sleep and hypnoticinduced sleep. Neuroscience, 141, 371-378.

Wróbel, A., Ghazaryan, A., Bekisz, M., Bogdan, W., \& Kaminski, J. (2007). Two streams of attention-dependent beta activity in the striate recipient zone of cat's lateralposterior-pulvinar complex. J. Neurosci., 27, 2230-2240. 